\title{
E-readiness and Security in E-commerce: A Three-Dimensional Approach
}

\author{
Irenée Tiako Ngatcheu ${ }^{1}$ \\ ${ }^{1}$ University of Yaounde II / FSEG, Cameroon \\ Correspondence: Irénée Tiako Ngatcheu University of Yaounde II SOA, FSEG, Cameroon.
}

Received: July 13, 2020

doi:10.5539/ibr.v13n9p152
Accepted: August 13, $2020 \quad$ Online Published: August 25, 2020

URL: https://doi.org/10.5539/ibr.v13n9p152

\begin{abstract}
E-commerce is globalizing. It is no possible to a country to emerge without it. That is why the vast majority of the world's countries adopt it. The purpose of this paper is to highlight the factors that impact e-readiness and e-commerce security. To achieve this objective, data have been collected on a sample of 40 cameroonian companies based in Douala and Yaoundé. The number of companies by business sector respects the proportions from the census conducted by the National Institute of Statistics (NIS) in 2016. The collected data are then analyzed using statistical software such as STATA to highlight the weight of each dimension. As results, E-readiness depends on legal factors, economic factors and technological factors.

So, E-readiness is based on three pillars: legal, economic and technological. None of the three is to be overlooked in the development of e-commerce.
\end{abstract}

Keywords: e-commerce, e-commerce security, e-readiness, economic factors, legal factors, technological factors

\section{Introduction}

The rapid development of e-commerce, and the enormous stakes that this trade generates, exposes it to fraud and embezzlement (Fevad, 2018), (Foucher S., 1998, p 177). For example, the Nepad has launched a campaign to enforce e-commerce infrastructure to make them less vulnerable (Nepad, 2017). The delay in Information and Communication Technology negatively affects many e-commerce players. These include governments, businesses and consumers. A deep reflection on e-commerce cannot be done without the cooperation of these players. It is a question of detecting and taking into account the aspirations of these different actors in economic life, avoiding proposing a solution that will not be adopted by the main players, even if it is very good.

The turnover of e-commerce continues to grow. It reached in 2019, the figure of 3.3 Trillions dollars (Kinsta, 2020). This is an increase of $17,85 \%$ compared to 2018. It is estimated that $95 \%$ of purchases will be made online by the year 2040 according to the same source.

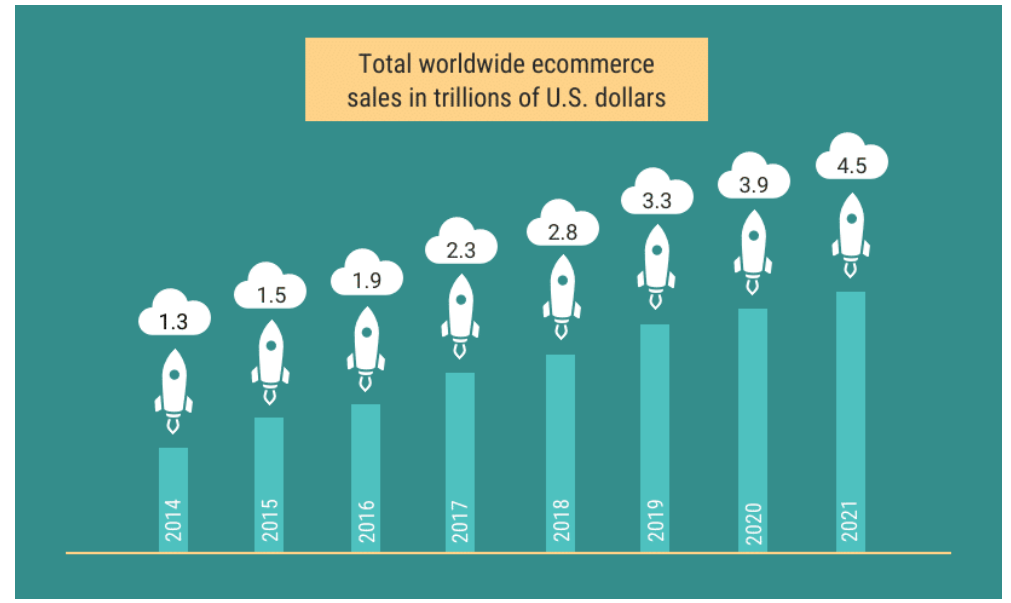

Figure 1. Global e-commerce growth in trillions of dollars

Source: kinsta 2020 
As the stakes are higher and higher, there is a greater risk of embezzlement. Hence the need to focus on safety. Security is addressed in its entirety and the main axes are determined. Several works are being done on safety but we find that this work focuses on a single axis, forgetting that safety is a whole and that no axis should be neglected.

Some authors put emphasis on client authentication (Jong , 2012, pp. 364 -376). Emails that are used along the transactions for e-commerce are secure by (Jung S. L. \& Kum S. L. , 2012, pp. 388-396). They specialized theirs work on emails. The band's manager allocates and controls keys in the group. Here a user not in the group cannot do e-commerce. E-commerce security issues are present by (Revati et al , 2015, pp 12896-12901). E commerce security tools are studies. But a global analysis is not done to protect the entire e-commerce. The actors that can be attack here are buyer and merchant. The analyzis is based on service oriented architecture that cannot covert all the aspects of e-commerce. Eye-tracking method is also use to improve the usability of e-commerce websides. More a site is usable, more it can be attack (Kaysi B. \& Topaloglu, 2018).

The architecture of software defined networking (SDN) introduces a particular distributed denial of service (DdoS) attacks that can affect or even overwhelm the SDN network (Yang et al , 2018, pp. 389-394).

The directions for e-commerce security in order to improve customer confidence in e-commerce shopping are provide by (Khan \& Shazia, 2019).

The concept of digital service failure from the perspective of expectation-conformation theory, develop an Archimate architecture model and use it to design a typology of technological enablers (technologies and technological approaches) that can be used by businesses and their customers to prevent service failures at different stages of online purchase via e-commerce websites (Nili A. et al , 2019).

A light on E-commerce privacy, security, its purpose, different security issues and how consumer's trust and purchasing behavior is affected by it are present by (Palak G. \& Akshat D., 2016, pp. 224-232).

Security problems in cloud computing systems and how to solve these problems using a quantitative security risk assessment model named Multi-dimensional Mean Failure Cost (M2FC) are develop by (Jouini M \& Rabai L. B. , 2017, pp. 249-263) . In fact, they summarize first security issues related to cloud computing environments and then propose a generic framework that analysis and evaluate cloud security problems and then propose appropriate countermeasures to solve these problems. All of those researchs develop not more than two aspects of tree aspects that exists.

It's about bringing out the safe weight it has on e-commerce for each dimension. This study is being done in a developing country and particularly in Cameroon.

According to United Nations Conference on Trade and Development, Cameroonian society and developing countries have some reservations about the appropriation of e-technologies (e-commerce, e-banking, e-business, e-government, etc.) (UNCTAD , 2018), these technologies are essential for the globalization to which any country that wants to develop aspires. With the challenge of a global pandemic, UNCTAD created a e-government platform to help countries to stay open for business during Covid 19 (UNCTAD , 2020). Only countries with a good level of ereadiness will be able to take advantage of this opportunity. Large structures take some ownership of it, but much remains to be done to reach an acceptable level. Individuals, for their part, have not yet fully realized this new technology. Would these reluctance and slow appropriation be due to a poor control of security? The safety axes and weights affected will allow safeness to be taken into account in its entirety for any e-commerce project.

In terms of context, the question arises: What are the pillars on which the security of e-commerce is based? In other words, is there a link between security and e-readiness? To answer this question, we have developed a methodology that we believe is appropriate for collecting and analyzing the data.

\section{Methodology}

As part of the methodology, a questionnaire was developed to investigate 40 companies that we selected. The selection was made between companies operating in areas for which developing countries could rely to begin their emergence (Statistiques mondiales, 2018). Dionne's work presents a synopsis of the different methods of gathering information. In this survey, we select the analysis of the numerical data (Dionne, 1998). This allows information to be collected, viewed and aggregated to analyze. The questionnaire is constructed according to the rigorous method proposed by (Bachelet, 2007) which breaks down the concept into dimensions and then into components. Sampling uses the quota method. These quotas are those issued by the general census of Cameroonian companies made in 2016. 
The interview itself took into account the three types of interviews (open interview, closed interview and semi-direct interview), depending on the questions asked. The data collected by the methods developed are of two types, depending on the methods used: quantitative methods and qualitative methods. The rest of the methodology first presents the model of the relationship between ereadiness and security. Second, we present the modelling criteria at the scale of quantification and the criteria for quantification-wide modeling. Third, law enforcement for the protection of people and property is present, fourth we present the method of analysis.

\subsection{Ereadiness - Security Model}

The Ereadiness assesses and enhances e-commerce with all related elements: the population ratio, IT and telecommunications infrastructure, postal services, etc. ( Institut National de la Statistique [INS], 2015) (Bridge , 2019). Security, on the other hand, takes into account the legal aspects (electronic signature, authentication), the economic aspects (security and protection of property, the most valuable) and the purely scientific aspects (security protocols, encryption algorithm). The effects sought by the combination of the concepts of Ereadiness and Security. The concepts of E-readiness and safety are strongly linked in our model.

Indeed, being ready for e-commerce presupposes that several aspects of security have been tested in a sustainable way, as the system is bound to continue. Thus E-readiness (E) will be tested according to security (S) and time. Security will be an association of several types of security: Legally J, Economicaly E, Technologically $\mathrm{T}=\mathrm{P} \oplus \mathrm{C}$. The technology plan takes into account security protocols $(\mathrm{P})$ and encryption algorithms $(\mathrm{C})$.

The operator $\oplus$ means that it is one of the two criteria or both.

$$
\begin{aligned}
\text { As well, } \quad \mathrm{E}= & \frac{d(S)}{d t}=\frac{d(J)}{d t}+\frac{d(E)}{d t}+\frac{d(\mathrm{P} \oplus C)}{d t} \\
\mathbf{E} & =\alpha \mathbf{S}=\boldsymbol{\beta} \mathbf{J}+\boldsymbol{\gamma} \mathbf{E}+\mu(\mathbf{P} \oplus \mathbf{C})
\end{aligned}
$$

Through this construction, we draw on the work of Druel (2007) which determine how a certain level of creativity can be maintained over time by defining the notions of attractiveness and sustainability, the second being the derivative of the first over time.

\subsection{Criteria for Modeling and Quantification Scale}

\subsubsection{E-readiness Assessment Criteria}

The following criteria are used to assess e-readiness

(i) Bank coverage is one of the key links in e-commerce. The number of banks characterizes a fluid e-commerce, the spatial distribution is not necessarily useful. The reliability of the banking system is unavoidable. The same is true of citizens' proximity to banks. The fee charged when opening the account can be a motivating or discouraging factor.

(ii) The reliability of the telecommunications system is of paramount importance. Telecommunications are essential for e-commerce. Different actors use this method to send messages. When access to telecommunications is sufficient, the extension of e-commerce may be possible. The coverage of Cameroonian territory gives the possibility of e-commerce in all cities and even villages of the country.

(iii) Mobile network coverage reinforces the fixed network in order to make data transfers as easy as possible.

(iv) The extension of Internet access gives everyone the opportunity to participate in e-commerce. Do cyberspaces, computer labs, etc. provide sufficient access to the Internet? Anyone who would like to connect to the Net can have access.

(v) The good mobile density TV gives multiple people the ability to complete their transactions without being interrupted in their transactions due to lack of connection. Mobile coverage of regions is crucial.

(vi) The number of computers is crucial for an effective start-up of e-commerce. The ratio per capita, compared to developed countries or at least the highest ratio. The effective start-up of e-commerce depends on the number of computers. As "African solidarity" helps, access to computers could be achieved through an acquaintance (family members, friends, etc.) which is also an asset for access to the computer tool.

(vii) Internet connections. The Internet connection rate is just as crucial for the implementation of e-commerce. Access should be possible for potential sellers as well as potential customers. The first for the online release of 
their products and communication with customers. The second to place product orders and then interact with the seller.

\subsubsection{Safety Assessment Criteria}

(i) Any e-commerce player must have an account in a bank. Hence the need to have a sufficient number of banks and especially banks with good capacity.

(ii) E-commerce security takes into account the protocol used. The protocols SET, C-SET, ECOMM, HTTPS, SSL are generally used. Standard algorithms such as DES, RSA, GPG are applied.

(iii) Law enforcement is present for the protection of people and property.

\subsection{Law Enforcement Is Present for the Protection of People and Property}

\subsubsection{E-readiness Criteria}

(i) The greater the Internet bandwidth, the smoother the data transfer;

(ii) IT and telecommunications infrastructures linked to e-commerce depend on electrical energy. Electrical energy is an essential element for e-commerce. To intervene in e-commerce regardless of the region or city, the need for electrical energy arises;

(iii) The telephone cost is unavoidable in terms of the extension of e-commerce. This parameter necessarily increases the cost of an ordered item, if the price is very high, e-commerce will be limited to a small minority;

(iv) The human resources available to the country for the start-up of e-commerce is a very important factor. The provision of merchant sites is made by local resources who are responsible for making available to the whole world the products from our industries. Human resources will be equally important and even crucial in the production of these goods and services to be made available to the whole world;

(v) The banking system should be very reliable;

(vi) Postal infrastructure will have to be of very good quality to ensure deliveries. The goods purchased will be distributed by postal companies. All purchases made should be delivered by the postal services. This is an opportunity to check whether postal structures cover all regions of the country;

(vii) The housing location plan is a key role. For the vast majority, the location plan is unreliable or generally non-existent. However, it is an essential element for the delivery of purchased products;

(viii) Road infrastructure is just as essential. Delivery of goods is only effective if it is done on time. This will prevent the expiration of perishable products and foodstuffs. These deadlines can only be met if the road infrastructure is of good quality. Let all regions be accessible regardless of the season.

\subsubsection{Security Criteria}

(i) The banking system needs to be more and more secure. E-commerce requires the seller and the customer to each have their own bank. Since these players have kept their assets in these banks, trust can only be established around e-commerce if these different assets are safe;

(ii) Authentication is a must. Authentication is usually done by password. The introduction of biometrics is gradual ;

(iii) Electronic signature is also present. Ensure that a transaction is actually signed electronically. An essential element for any transaction to be authentic and indisputable;

(iv) The property will need to be well preserved throughout the handling, taking into account the fragility and conservation conditions. Throughout the transport of goods, the right conditions of preservation will have to be applied.

(v) The protection of products from theft and embezzlement must be ensured;

(vi) The secret must be assured. Any transaction should not be accessed by unauthorized persons;

(vii) The replay must be insured to avoid making the same transactions several times and maliciously;

(viii) Non-repudiation is ensured to prevent the renouncing of a commitment made in e-commerce;

(ix) Electronic payment ;

(x) The electronic transport of money must be secure;

(xi) Security protocol ; 
(xii) Encryption algorithm.

Table 1 provides a classification of the different e-readiness and security criteria for e-commerce. This classification includes quantitative and quantitative elements. These criteria are part of the questionnaire and are subject to appropriate treatments depending on whether they are quantitative or qualitative.

Table 1. Classification of e-readiness and security criteria in e-commerce

\begin{tabular}{|c|c|c|}
\hline Axes & Nature of the criteria & Criteria \\
\hline \multirow{16}{*}{ E-readinesss } & Quantitative & Telephone lines \\
\hline & & Internet density \\
\hline & & Mobile density \\
\hline & & Percentage of computers / number of computers \\
\hline & & Tele centers \\
\hline & & Mobile density \\
\hline & & Internet Connexion \\
\hline & & Mobile coverage \\
\hline & & Internet penetration rate \\
\hline & Qualitative & Human ressources \\
\hline & & Banking system \\
\hline & & Postal infrastructure \\
\hline & & Housing location plan \\
\hline & & Road infrastructure \\
\hline & & Electricity \\
\hline & & Telephone cost \\
\hline \multirow[t]{16}{*}{ Security } & Quantitative & Number of banks \\
\hline & & E-commerce protocol \\
\hline & & Packing structure \\
\hline & & Security protocol \\
\hline & & Encryption algorithms \\
\hline & & Law enforcement, physical security \\
\hline & & Encryption algorithms \\
\hline & Qualitative & Authentication \\
\hline & & Electronic signature \\
\hline & & Protection of property \\
\hline & & Product security \\
\hline & & Bank security \\
\hline & & Electronic payment \\
\hline & & Secret \\
\hline & & Replay \\
\hline & & Non-repudiation \\
\hline
\end{tabular}

Source : e-readiness survey

\subsection{Method of Analysis}

\subsubsection{Results Estimation Procedure}

First, we estimate the relationship between e-readiness and different aspects of e-commerce. Either Yi the binary variable reflecting the level of satisfaction of the e-readiness of a given company. It looks like following:

$\mathrm{Yi}=1$ if the company is satisfied with the e-readiness and $\mathrm{Yi}=0$ if it is not satisfied with the e-readiness.

The model used is a logit binomial model. The Yi variable is the variable explained, i.e. e-readiness and explanatory variables, legal, economic and technological aspects are translated by Xi. The model comes in the following relationship:

$$
Y_{i}=\beta_{0}+\beta_{i} X_{i}+\varepsilon_{i}
$$

$\boldsymbol{\varepsilon}_{\boldsymbol{i}}$ is the model's error term.

\subsubsection{Sampling}

The evaluation method was based on a study of 40 Cameroonian companies with at least 3 employees. First, we have identified Cameroonian companies, a ranking is made by category or sector of activity. The number of companies selected for the questionnaire is proportional to the category representation proposed by the general census of businesses in Cameroon (RGE-2 , 2018). An effort is made for the spatial/regional distribution of 
societies.

The purpose of this survey is to determine the e-readinness of Cameroonian companies. An emphasis is placed on the sectors cited by UNCTAD, in this case crafts, agriculture, tourism [UNCTAD , 2015]. Banks and micro-financial structures, for their part, intervene in the financial platform. All this in order to define the degree of perception of e-commerce by the Cameroonian industrial world. The results can serve as a dashboard for decision-makers in the administration. The work was carried out in Cameroon's two major cities (Douala and Yaounde). Twenty-four companies for Douala and sixteen for Yaounde.

According to the last general census of companies conducted by the National Statistical Institute (NSI) in 2016, the city of Douala accounts for $33.5 \%$ of all national companies compared to $23.9 \%$ for Yaounde [14]. By taking a discount from the entire study on the two cities, the following percentages are obtained: Douala $\left(\frac{33,5}{33,5+23,9}=\right.$ $58,4 \%)$ Yaounde $\left(\frac{23,9}{33,5+23,9}=41,6 \%\right)$. That's about $40 \%$ in Yaounde and $60 \%$ in Douala. In the sequel we will work with this approximation.

Each type of activity is assigned the number of companies surveyed in Yaounde and Douala. The aim is to make a distribution that respects the quotas derived from the business census. As the table below illustrates.

Table 2. Quotas allocated to businesses based on the type of activity.

\begin{tabular}{lllll}
\hline \multirow{2}{*}{ Type of activity } & \multicolumn{2}{c}{ Town of residence } & \multicolumn{2}{c}{ Total } \\
\cline { 2 - 4 } & Yaounde & Douala & & \\
\hline Banks/Micro finance & 8 & 10 & 18 & $46 \%$ \\
Agriculture & 0 & 1 & 1 & $2 \%$ \\
Transport/Tourism & 4 & 8 & 12 & $30 \%$ \\
food industries & 4 & 5 & 9 & $22 \%$ \\
Total & 16 & 24 & 40 & $100 \%$ \\
& $40 \%$ & $60 \%$ & $100 \%$ & \\
\hline
\end{tabular}

Source: e-readiness survey

\section{Results}

According to the table below, at the 5\% threshold, we have good reason to say that there is a dependent relationship between e-readiness and other aspects. In other words, the different legal, economic and technological aspects individually have a significant influence (at the threshold of 5\% to be wrong) on e-readiness in Cameroon.

Table 3. Chi-square test results

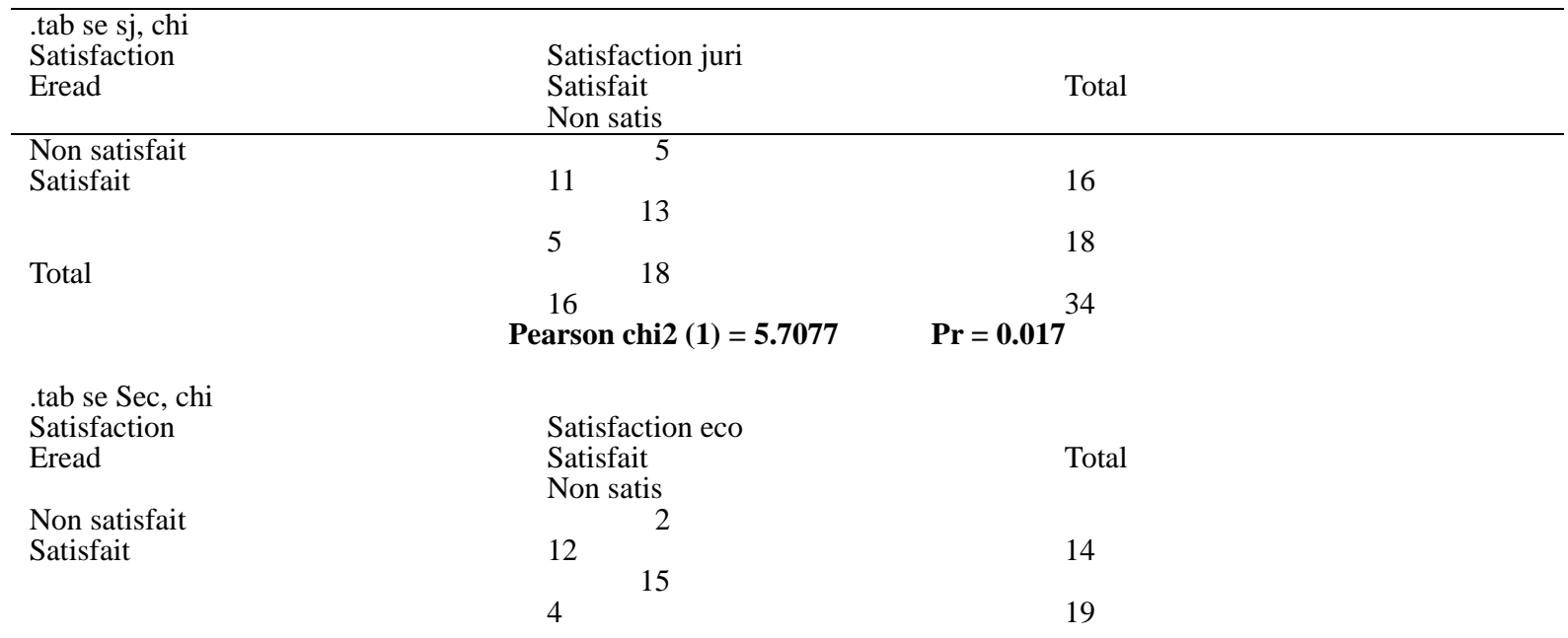




\begin{tabular}{|c|c|c|}
\hline Total & $\begin{array}{l}\text { 16 } 17 \\
\text { Pearson chi2 }(\mathbf{1})=\mathbf{1 3 . 4 9 3 4}\end{array}$ & $\operatorname{Pr}=0.000$ \\
\hline $\begin{array}{l}\text {.tab se st, chi } \\
\text { Satisfaction } \\
\text { Eread }\end{array}$ & $\begin{array}{l}\text { Satisfaction tech } \\
\text { Satisfait } \\
\text { Non satis }\end{array}$ & Total \\
\hline $\begin{array}{l}\text { Non satisfait } \\
\text { Satisfait }\end{array}$ & $\begin{array}{cc}12 & 2 \\
4 & 13 \\
16 & 15 \\
\text { Pearson } & \text { chi2 }(1)=\mathbf{1 1 8 8 7 7}\end{array}$ & $\begin{array}{r}14 \\
17 \\
31\end{array}$ \\
\hline
\end{tabular}

Source: Authors from STATA outputs

The aim here is to test the zero $\mathrm{H} 0$ hypothesis that "all coefficients of explanatory variables are zero" against the alternative hypothesis H1 "There is at least one variable with a coefficient different from zero". In this case, we use the model's khi-two test (LR chi2) whose p-value allows to reject H0 if it is significant. We find that the model is generally significant according to Table 4 (p-value - 0.0002 less than 5\%). So there is at least one variable that significantly influences business satisfaction on e-readiness (table 4).

Table 4. Result of Logistic Regression

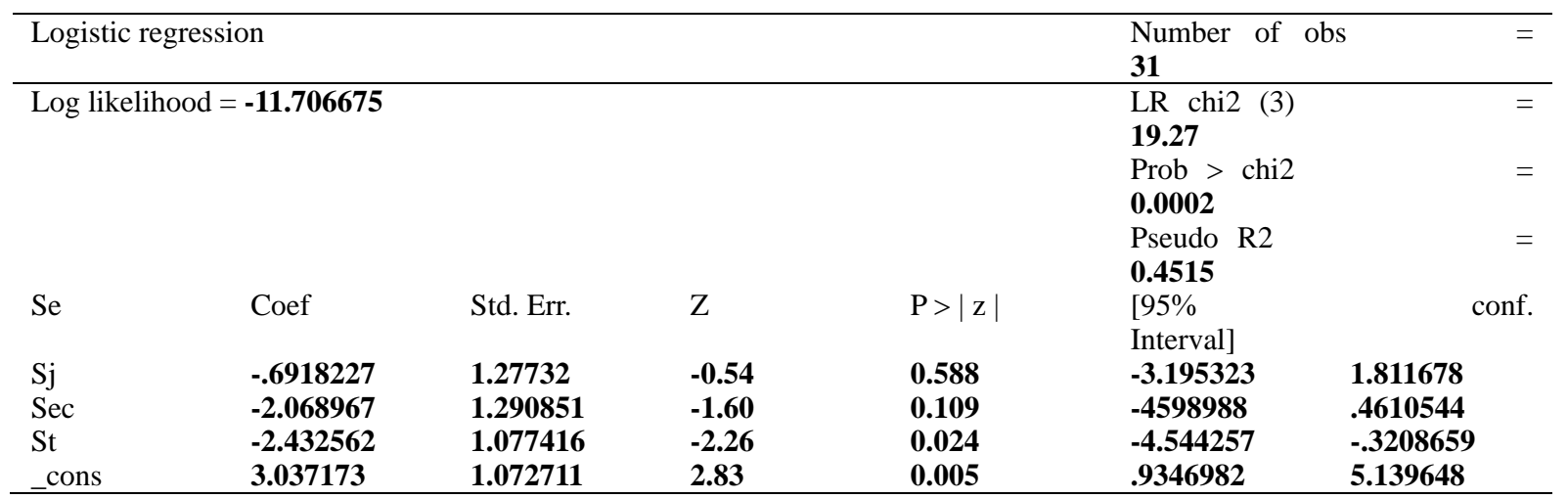

Source: Authors from STATA outputs

For the overall adjustment of the model, we used the Hosmer and Lemeschow test (table 5). The results show that the value of this test is $26.84 \%$ well above $5 \%$. As a result, it is concluded that the model is well adjusted.

Table 5. Hosmer and Lemeshow Test

Logistic model for se, goodness-of-fit test

(Table collapsed on quantiles of estimated probabilities)

(There are only 6 distinct quantiles because of ties)

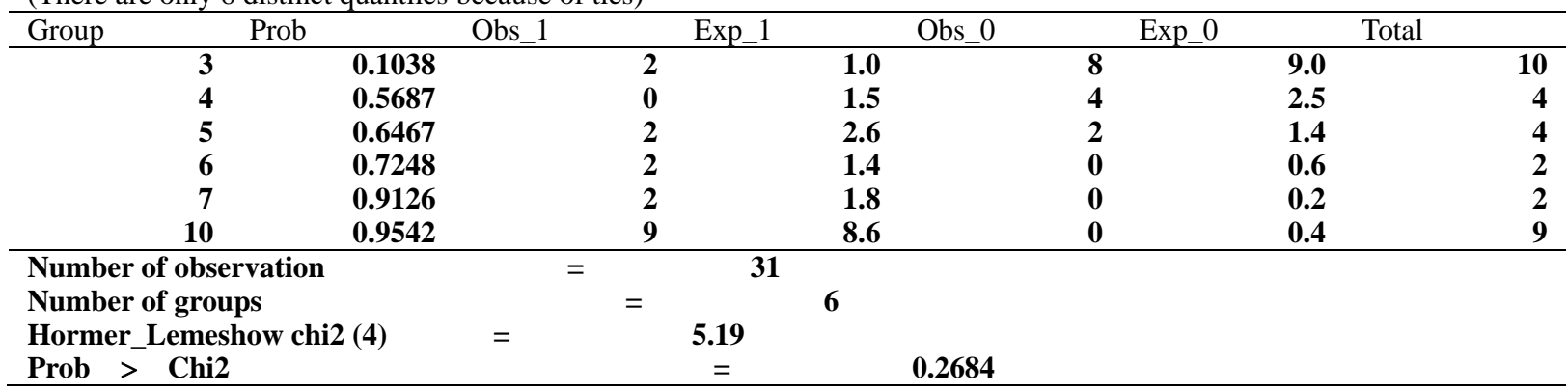

Source: e-readiness survey 
The probabilities estimated by logistic regression make it possible to classify companies as "satisfied" and "unsatisfied" in relation to e-readiness, based on a fixed break value, here $\mathbf{0 . 5}$; standard generally used. When a company's probability of being satisfied with e-readiness exceeds this threshold, the model affects that company in the group of satisfied companies. Table 6 shows that the model has a predictive power of $\mathbf{8 0 . 6 5 \%}$. In other words, the model well predicts a company's satisfaction with e-readiness in more than four out of five cases. Moreover, the probability of being effectively satisfied knowing that one was classified as such is $\mathbf{7 8 . 9 5 \%}$ while the probability of being effectively unsatisfied knowing that one was classified as unsatisfied is $\mathbf{8 3 . 3 3 \%}$.

Table 6. Model Classification Table

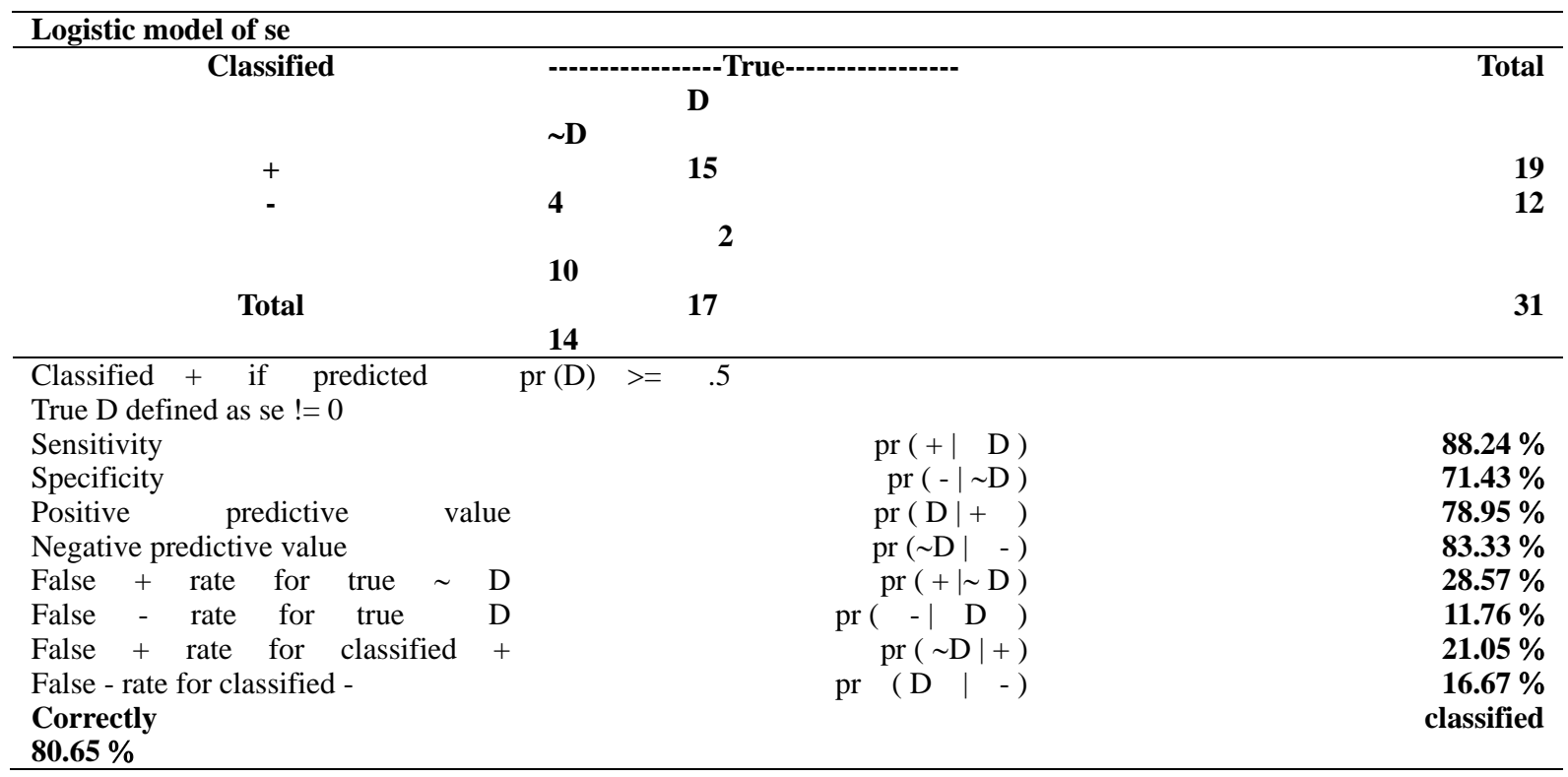

Source: e-readiness survey

As an indicator of the model's ability to discriminate we have the ROC curve. It is the graphic representation of sensitivity according to (1 - specificity) which represents the risk of classifying a non-optimistic among the optimists; sensitivity being the probability of classifying an optimistic individual in the optimistic group (figure 2). The area below the ROC curve being $90.76 \%$, we can say that the discrimination of the model is excellent.

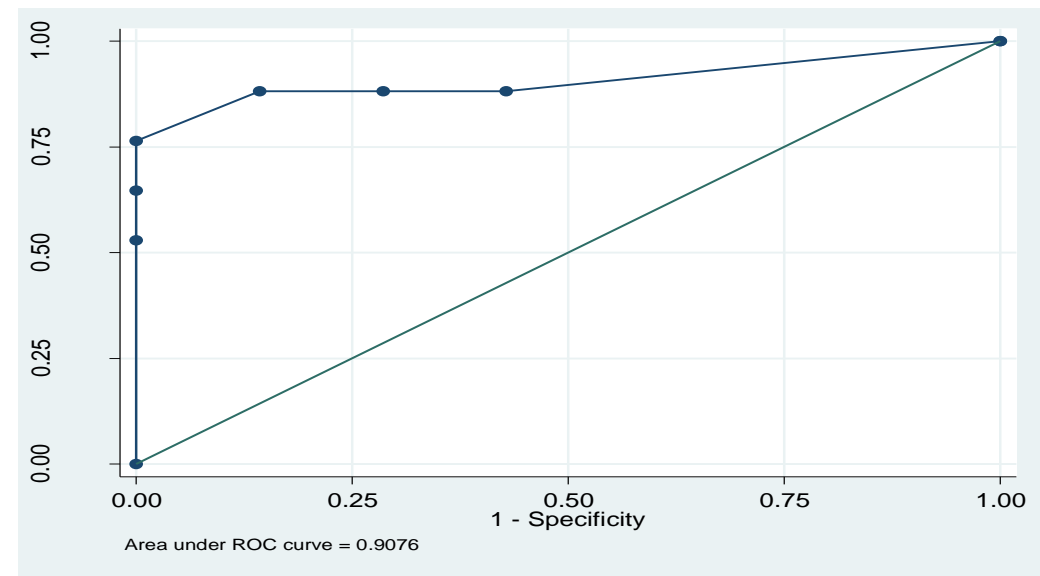

Figure 2. Model 1 ROC curve

Source: Authors from STATA outputs

It is clear from this model that whether or not to be satisfied with e-readiness is independent of whether or not to be satisfied with the legal aspect of e-commerce (sj). Indeed, the latter proved to be insignificant (even with a 15\% 
risk of getting it wrong) at the end of the model. Satisfaction with the other two aspects of e-commerce (Sec and st) is found to have a significant $15 \%$ influence on e-readiness. The following interpretations are:

Business satisfaction with e-readiness differs significantly depending on the satisfaction on the economic side of e-commerce. Indeed, when one goes from a satisfied company on this aspect (economic e-commerce) to another uns satisfy, the probability of being satisfied with e-readiness decreases by 87.36. The level of satisfaction of companies on e-readiness depends heavily on their satisfaction with the technological aspect of e-commerce. Indeed, a company satisfied with the technological aspect is 11.38 times more likely to be satisfied with e-readiness than a company unsusfied with the technological aspect.

Table 7. Chance Report (for interpretation)

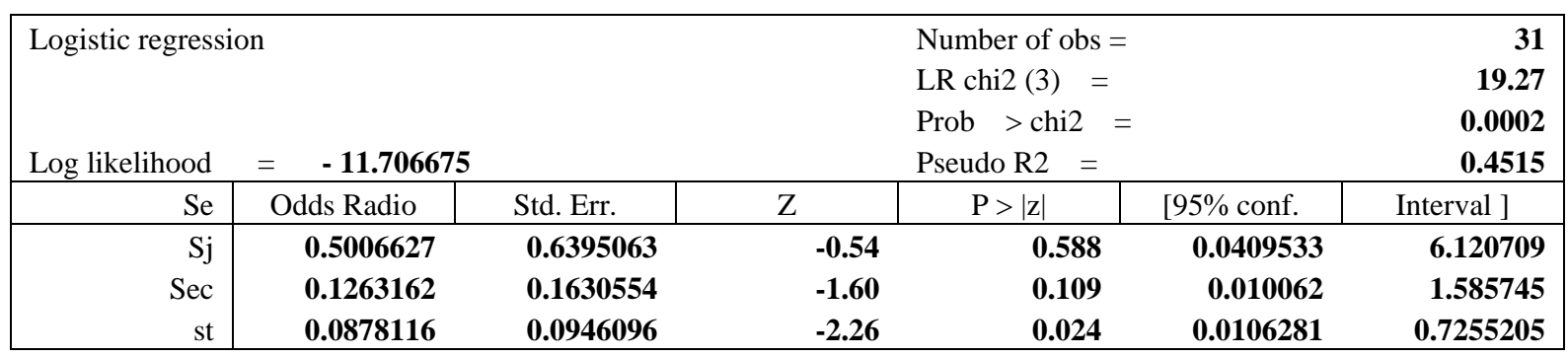

Source: Authors from STATA outputs

We then have the following:

$\mathrm{E}=-\mathbf{0 , 6 9 1} * \mathrm{~J}-2,068 * \mathrm{Ec}-2,432 * \mathrm{~T}+3,037$

E-readiness thus depends on legal, economic and technological factors. Only the signs assigned to the coefficients are interpreted. Thus, when a company's likelihood of being satisfied with one aspect of e-commerce increases (legal, economic and technological aspects) the likelihood of being satisfied with e-readiness decreases.

For the company, such a result may have the following repercussions on the company: (i) IT and telecommunications service companies focus on the technological aspect of security (Public Key Infrastructure), neglecting the economic and legal aspects which leaves a security flaw; (ii) Regulators, on the other hand, place particular emphasis on the legal aspect of security; (iii) Financial structures, for their part, focus on the economics of security.

All of these structures should value all three aspects of safety. This avoids leaving a security feature that will weaken security in general.

Subsequently, we estimated the model highlighting the link between e-readiness and business identification and e-commerce knowledge variables. The purpose of this estimate is to establish a logistic regression relationship between the e-readiness variable and the characteristics of the company and those of e-commerce knowledge.

$\mathrm{E}=f$ (business identification variables and knowledge of e-commerce). 
Table 8. List of variables likely to enter the model

\begin{tabular}{|c|c|c|c|}
\hline Variables & Label & Terms & $\begin{array}{l}\text { Betterment (chi } \\
\text { two test) }\end{array}$ \\
\hline Ville & Town of residence & Yaoundé, Douala & $3,9 \%$ \\
\hline Sect-act & Activity area & Secondary, Tertiary & $9,6 \%$ \\
\hline stat_ju & Legal statut & $\begin{array}{l}\text { Public limited company, limited liability } \\
\text { company }\end{array}$ & $66,7 \%$ \\
\hline Typ_activ & Type of activity & $\begin{array}{l}\text { Banks, Agriculture/agribusiness, Tourism, } \\
\text { Other activity }\end{array}$ & $29,1 \%$ \\
\hline Ancienneté & Company seniority & Less than 10 years, more than 10 years. & $66,8 \%$ \\
\hline Chiff_aff & Turnover & Less than 50 million, More than 50 million & $9,1 \%$ \\
\hline Connexion_net & Internet accessibility & yes, No & $16,9 \%$ \\
\hline Site_net & Webside ownership & yes, No & $46,4 \%$ \\
\hline Recours_e_com & Use of e-commerce & Yes, No & $26,8 \%$ \\
\hline Opération & Company operation & $\begin{array}{l}\text { Electronic Money Transfer, Online Buying, } \\
\text { Other Transaction }\end{array}$ & $37,2 \%$ \\
\hline App_service & Appreciation of service & Satisfied, Promising, Unsatisfied & $13,6 \%$ \\
\hline Raison_opt & Reason e-commerce option & Time Gain, Availability, Other Reason & $32,2 \%$ \\
\hline Structure & E-commerce trading structure & $\begin{array}{l}\text { Person to person, Business to person, } \\
\text { Person to business }\end{array}$ & $82,6 \%$ \\
\hline Moyen & Means of payment & $\begin{array}{l}\text { Bank card, Electronic Currency Door, } \\
\text { Other Way }\end{array}$ & $66 \%$ \\
\hline Nbr_empl & Company size & Keep on going & - \\
\hline
\end{tabular}

Source: e-readiness survey

The model retains variables with a value of less than or equal to $15 \%$ (the level of risk set in the previous model). This level of risk has been set at $15 \%$ given the rarity of the phenomenon (table 8 ). Thus, we took the variables "City," "Sect-act," "Chiff_aff," "App_service" and "Nbr_empl." The best model is one that does not take into account the two variables "Chiff_aff" and "App_service."

The overall significance of the model is verified from Fischer's test on the model (table 9)

Table 9. Significant model testing

\begin{tabular}{|c|c|c|c|c|c|c|}
\hline Logistic regress & - 19.084094 & & & $\begin{array}{l}\text { Number of obs }= \\
\text { LR chi2 }(3)= \\
\text { Prob > chi2 }= \\
\text { Pseudo R2 = }\end{array}$ & & $\begin{array}{r}35 \\
10.09 \\
0.0178 \\
0.2092 \\
\end{array}$ \\
\hline $\mathrm{Se}$ & Odds Radio & Std. Err. & $\mathrm{Z}$ & $\mathrm{P}>|\mathrm{z}|$ & {$[95 \%$ conf. } & Interval ] \\
\hline Ville & 2.011886 & 0.923266 & 2.18 & 0.029 & 0.202318 & 3.81454 \\
\hline nbr_empl & 0.0018962 & 0.0011117 & 1.71 & 0.088 & -0.0002828 & 0.0040752 \\
\hline Sect_act & -2.291169 & 1.309943 & -1.75 & 0.080 & -4.858611 & 0.2762719 \\
\hline cons & -0.8122433 & 0.6305099 & -1.29 & 0.198 & -2.04802 & 0.4235335 \\
\hline
\end{tabular}

Source: Authors from STATA outputs

It appears that the model is generally significant, with a gain of $\mathbf{0 . 0 1 7 8}<\mathbf{5 \%}$. Therefore, we have good reason to believe that the model specified above is overall significant.

Table 9 shows that the value of this test is $49.01 \%$, well above 5\%. As a result, it is concluded that the model is well adjusted. The hypotheses of this test are: 
Table 10. Hosmer and Lemeshow Test

\begin{tabular}{|c|c|c|c|c|c|c|}
\hline \multicolumn{7}{|c|}{$\begin{array}{l}\text { Logistic model for se, goodness-of-fit test } \\
\text { (Table collapsed on quantiles of estimated probabilities) }\end{array}$} \\
\hline Group & Prob & Obs_1 & Exp_1 & Obs_0 & Exp_0 & Total \\
\hline 1 & 0.2299 & 1 & 0.7 & 3 & 3.3 & 4 \\
\hline 2 & 0.3107 & 0 & 1.8 & 6 & 4.2 & 6 \\
\hline 3 & 0.3111 & 0 & 0.3 & 1 & 0.7 & 1 \\
\hline 4 & 0.3516 & 2 & 0.9 & 1 & 2.1 & 3 \\
\hline 5 & 0.5103 & 2 & 1.7 & 2 & 2.3 & 4 \\
\hline 6 & 0.7469 & 4 & 3.7 & 1 & 1.3 & 5 \\
\hline 7 & 0.7695 & 1 & 1.5 & 1 & 0.5 & 2 \\
\hline 8 & 0.7725 & 2 & 2.3 & 1 & 0.7 & 3 \\
\hline 9 & 0.7817 & 4 & 3.1 & 0 & 0.9 & 4 \\
\hline 10 & 0.9566 & 3 & 2.8 & 0 & 0.2 & 3 \\
\hline
\end{tabular}

Source: e-readiness survey

Table 10 shows that the model has a predictive power of $80.00 \%$. In other words, the model well predicts an individual's state of satisfaction with e-readiness in four out of five cases. Moreover, the probability of being effectively satisfied knowing that one was classified as such is $83.33 \%$ while the probability of being effectively unsatisfied knowing that one was classified as unsatisfied is $76.47 \%$.

Table 11. Model Classification Table

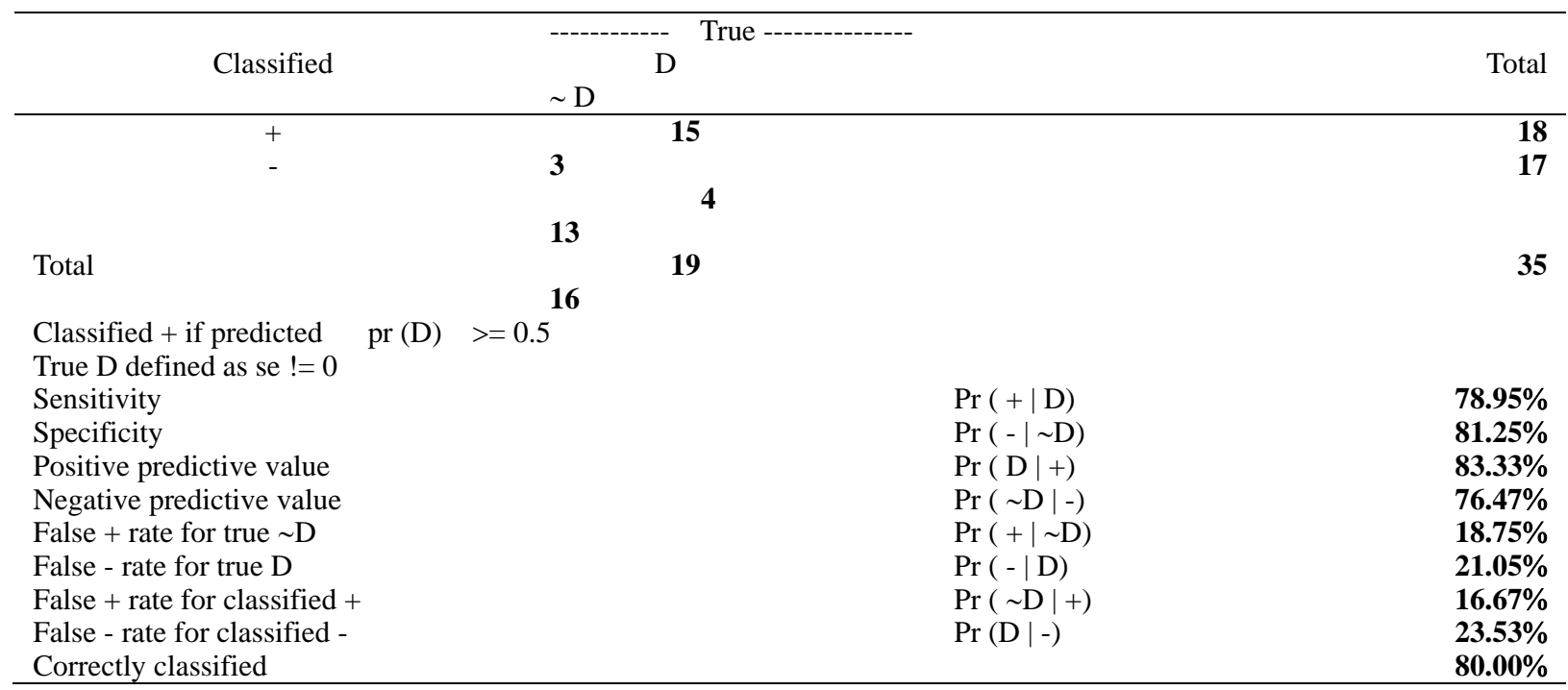

\section{Source: e-readiness survey}

The area under the ROC curve being $84.87 \%$, we can say that the discrimination of the model is excellent (figure 3).

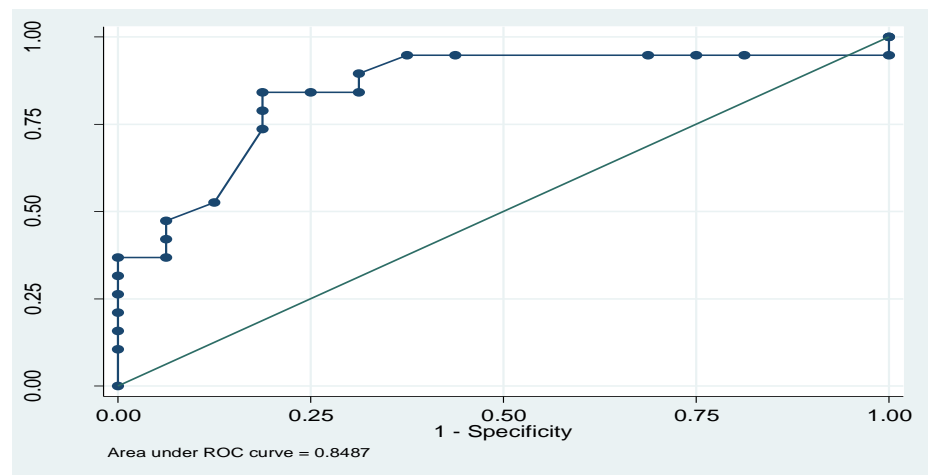

Figure 3. Model 2 ROC Curve

Source: e-readiness survey 
This model shows that the city of residence, activity area and number of employees have a significant influence on the level of satisfaction of e-readiness companies (table 12).

Table 12. Chance report (for interpretation)

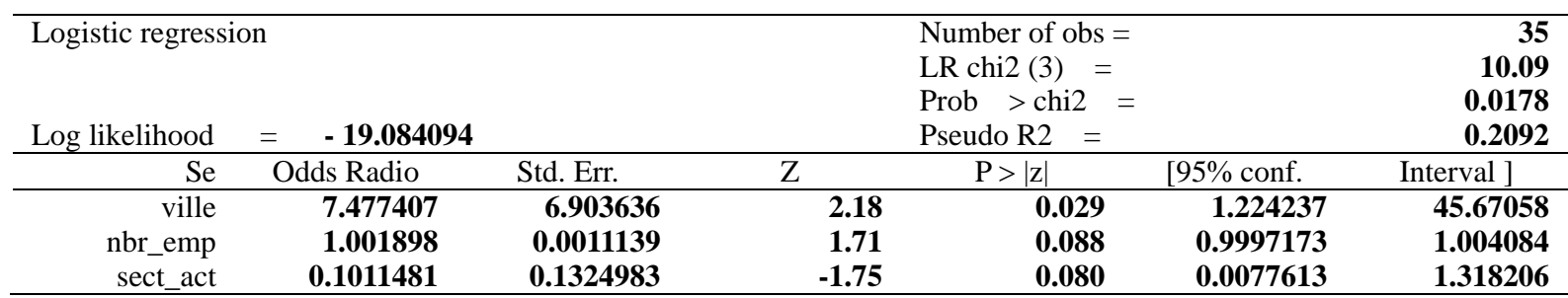

Source: e-readiness survey

\subsubsection{E-readiness and City of Residence}

The level of business satisfaction with e-readiness differs depending on the city of residence of the company. Indeed, when you move from a Yaounde company to a company in Douala, the probability of being satisfied with e-readiness increases. A company in the city of Douala, all things being equal, is 7.47 times more likely to be satisfied with e-readiness than a company in the city of Yaounde.

\subsubsection{E-readiness and Business Sector}

The business sector has a significant influence on the satisfaction of e-readiness companies. Indeed, when moving from one company in the secondary sector to another in the tertiary sector, the probability of being satisfied increases by $89.9 \%$. In other words, a secondary company is 9.8 times more likely to be satisfied with e-readiness than a firm in the tertiary sector.

\subsubsection{E-readiness and Size of the Company}

The number of employees in the company also influences the level of satisfaction of the company's e-readiness. As a result, when this number increases by one unit, the probability of being satisfied increases by $0.19 \%$.

\section{Conclusion}

We have demonstrated in this article that there is a link between e-readiness and security in e-commerce and that security in e-commerce has three components: the legal component, the economic component and the technological component. All three of these components are essential to the start of fair e-commerce. The industry and the number of employees influence the level of satisfaction in e-readiness. Today, e-commerce is an essential tool for business transactions. As the stakes are higher and higher, there is a risk of attack, espionage, or hacking of computer systems. This leads to the establishment of security mechanisms. Today, with the Covid 19 pandemie, e-commerce is becoming increasingly necessary in transactions. It must therefore be accompanied by safety measures to ensure their reliable use by users.

A similar study in another developing country will give us similar results. The results in developed countries will certainly not be very different.

\section{References}

Bachelet, R. (2007). Recueil, analyse et traitement des données (cours en ligne). École Centrale de Lille, Lille, 2007. Retrieved from http://rb.ec-lille.fr

Bridges. (2019). Comparison of E-Readiness Assessment Models. Retrieved from http://www.bridges.org/année

CNUCED, Conférence des Nations Unies sur le Commerce et le Développement (2018). Accroitre les gains pour le développement tirés du commerce électronique et les plates formes numériques. Groupe intergouvernemental d'experts du commerce électronique et de l'économie numérique. 18-20 Avril 2018 P17.

CNUCED, Conférence des Nations Unies sur le Commerce et le Développement (2015). "Outil Pédagogique des Grandes Tendances Mondiales depuis 1945 “ 2015.

CNUDCI, Commission des Nations Unies pour le Droit Commercial International (2013). Reglement d'arbitrage de la CNUDCI.

Dionne, B. (1998). Pour réussir, guide méthodologique pour les études et la recherche. Études vivantes. Ed. de 
l'université de Laval, 3e édition, 1998.

Druel, F. (2007). Evaluation de la valeur à l'ère du Web: proposition de modèle de validation des projets non marchands. Thèse de doctorat. Novembre 2007.

Economist Intelligence Unit. (2009). E-readiness Rankings 2009, the usage imperative. A repport of Economist Intelligence Unit, written in co-operation with the IBM Institut for Business Value. June 2009.

FEVAD, Fédération du e-commerce et de la vente à distance (2018). Bilan ventes à distance . E-commerce 7 fev 2018.

Foucher, S. (2011). Les statistiques du e-commerce mondial Articles infographiques 6 decembre 2011. 1998 IEEE Symposium on Security and Privacy. IEEE Computer Society Press, May 1998. 177.

INS, Institut National de Statistiques (2015). Annuaire Statistique du Cameroun. Chapitre 21: Poste et Télécommunication pp. 346-355 . Edition 2015.

Jong R. L., Shailendra, C. N., Karim, F., \& Jae, M. J., (2012). When do online shoppers appreciate security enhancement efforts? Effect of financial risk and security level on evaluation of customer authentification. International Journal of Human Computer studies, 364-376. https://doi.org/10.1016/j.ijhcs.2011.12.002

Jouini, M., \& Rabai, L. B. (2017). A Security Framework for Secure Cloud Computing Environments. Cloud Security: Concepts, Methodologies, Tools, and Applications pp. 249-263 2017. Hershey, PA: IGI Global. https://doi.org/10.4018/978-1-5225-8176-5.ch011

Jung, S. L., \& Kum, S. L. (2012). Robust e-commerce service: Light Weight Secure mail order mechanism. Elsevier, Electronic Commerce Research and Applications 2012, pp. 388-396. https://doi.org/10.1016/j.elerap.2012.04.001

Kaysi, B., \& Topaloglu, Y. (2018). Usability in e-commerce Websides ; results of eye tracking evaluation, World Academy of Science, Engineering and Technology. International Journal of Computer and Systems Engineering, 12(10).

Khan, S. W. (2019). Cyber Security Issues and Challenges in E-Commerce (January 6, 2019). Proceedings of 10th International Conference on Digital Strategies for Organizational Success. https://doi.org/10.2139/ssrn.3323741

Kinsta, (2020). Statistiques sur le ecommerce pour 2020, chatbots, voix, marketing omni-channel. Retrieved from www.kinsta.com/fr/blog/statistiques-ecommerce/

NEPAD, Nouveau Partenariat pour le Developpement de l'Afrique (2017). Agenda $5 \%$ pour le développement. Retrieved from http://www.jeuneafrique.com/475543/economie/le-nepad-veut-convaincre-les-investisseurs-institutionnelsde-miser-sur-les-projets-dinfrastructures/

Nili, A., Barros, A., Johnstone, D., \& Tate, M. (2019). Technological enablers for preventing services failure with e-commerce websites. In Proceedings of the 27th European Conference on Information Systems (ECIS), Stockholm \& Uppsala, Sweden, June 8-14, 2019. ISBN 978-1-7336325-0-8 Research Papers. Retrieved from https://aisel.aisnet.org/ecis2019_rp/123

Palak, G., \& Akshat, D. (2016). E-Commerce- Study of Privacy, Trust and Security from Consumer's Perspective. International Journal of Computer Science and Mobile Computing, 5(6), 224-232.

Revati, C., Shanthi, K., \& Saranya, A. R. (2015). A Study on the E-commerce Security Issues. International Journal of Innovative Research in Computer and Communication Engineering, 3, 12896-12901.

RGE-2, Recensement General des Enterprise (2018). Recensement General des Entreprises du Cameroun 2016 (RGE-2). Rapport des principaux résultats. Publié en 2018.

Statistiques, M. (2018). Base de Données sur l'Economie Mondiale, Statistiques mondiales 2018. Retrieved from www.statistiques-mondiales.com

UNCTAD, United Nations Conference on Trade and Development. (2015). Reforming International Investment Governance. World Investment Report 2015.

UNCTAD, United Nations Conference on Trade and Development. (2018). Investment and new industrial policies. World Investment Report. 2018.

UNCTAD, United Nations Conference on Trade and Development. (2020). How UNCTAD's e-government platform helps countries stay open for business during Covid-19. World Investment forum 2020. 
Wikipedia. (2019). Commerce électronique . Retrieved from http://fr.wikipedia.org/wiki/E-commerce

Yang, Z., Kangfeng, Z., Wei N., \& Ren P. L. (2018). An Earth Mover's Distance Algorithm Based DDoS Detection Mechanism in SDN. World Academy of Science, Engineering and Technology. International scholarly and scientific research \& innovation, 12(6), 389-394.

Webgraphy

http://www.readinessguide.org/guide.pdf.

www.wikipedia.org/wiki/e-commerce

\section{Copyrights}

Copyright for this article is retained by the author(s), with first publication rights granted to the journal.

This is an open-access article distributed under the terms and conditions of the Creative Commons Attribution license (http://creativecommons.org/licenses/by/4.0/). 